\title{
Assessing the Pollution Status of Jabi Lake in the Federal Capital Territory, Abuja, Nigeria
}

\author{
Ezeamaka Cyril Kanayochukwu, Sadiq Queen, Daful Mwanret, Ogbole Moses, and Anjide Theresa Wado \\ Department of Geography, Nigerian Defence Academy, Kaduna, Nigeria
}

Received: 2019-01-18

Accepted: 2019-11-18

\section{Keywords: \\ Jabi Lake; \\ Water; \\ Conductivity}

Correspondent Email: cyrilezeamaka@gmail.com

\begin{abstract}
This paper was aimed at providing the pollution status of Jabi Lake, Federal Capital Territory (FCT) Abuja. Thirteen parameters were tested from raw water collected four sampling points. The physicochemical parameters were measured using Hanna multiparametric meter. The concentrations of the metals were determined in triplicates. Flame atomic absorption spectrometer was used in the analysis as well as descriptive statistics (mean, standard deviation) and standard error. The Nigerian Industrial Standard (NIS) and World Health Origination (WHO) guidelines for domestic water were used to compare the results of the water from the lake. The study reveals that the mean turbidity ranged between $21.6-24.2-\mathrm{NTU}$ and is above the recommended limits of both WHO and NIS. The range of $\mathrm{pH}$ was between 6.3 and 8.8. $\mathrm{pH}$ is within the neutral range. The study reveals that the mean value of TDS and electrical conductivity is below the recommended limit of both WHO and NIS guidelines. The study shows that there is a high concentration of some heavy metals ( $\mathrm{Cd}, \mathrm{Cu}, \mathrm{Ni}, \mathrm{Mn}, \mathrm{Zn}$, and $\mathrm{Fe}$ ) in Jabi Lake. Cd, $\mathrm{Zn}, \mathrm{Fe}$, and $\mathrm{Ni}$ are above the permissible limits of the NIS and WHO guidelines, which is an indication of pollution. The study, therefore, recommends that proactive measures be taken on environmental laws in FCT and that environmental/health workers and non-governmental bodies be active in enlightenment campaigns that will alert members of the public to the harm being caused to this important ecosystem.
\end{abstract}

(C) 2019 by the authors. This article is an open access article distributed under the terms and conditions of the Creative Commons Attribution(CC BY NC) licensehttps://creativecommons.org/licenses/by-nc/4.0

\section{Introduction}

Water through the fluid is the basis of life and all primary need for all vital processes. This is because safe clean, and adequate freshwater is vital to the survival of all living organisms and the smooth functioning of ecosystems, communities, and economies (Obilonu et al., 2013). Water plays a significant role in the continuity of life due to its unique qualities. Water is an essential component of life that contains minerals that are extremely important in human nutrition and is critical for sustaining life. The significance of water to humans and other biological systems cannot be overemphasized, and there are numerous scientific and economic facts that water shortage or its pollution can cause a severe decrease in productivity and deaths of living species (Garba et al., 2010).

Sharma (2010) defines water pollution as the addition of excess undesirable substances to water that makes it harmful to man, animals, and aquatic life, or otherwise causes significant departures from the normal activities in or around water. Pollution decreases the suitability of water resources, thus, disturbs the normal use of water for irrigation, agriculture, industries, public water supply, and aquatic life. Pollution not only makes freshwater undrinkable but also unsuitable for industrial and agricultural purposes (Joshua and Nazrul, 2015). The main impact of water pollution is mainly water-borne diseases such as diarrhea, typhoid, and others, which can lead to death (Butu and Sadiq, 2016).

With increasing industrialization and population growth, watersourcesavailableforvariouspurposes, such as drinking, recreation, agriculture, and aquaculture, have been adulterated with industrial as well as animal and domestic wastes. As a result, it has become the most important means of transmission of several infectious diseases. Polluted sewage contains solids and dissolved organic compounds that impact an offensive odor and serves as an excellent medium for bio-magnifications of toxic substances to Primary, Secondary, and Tertiary consumers in trophic interactions (Aneja, 2005). Pollution of water bodies could occur due to run-offs flowing through agricultural areas where fertilizers and pesticides may have been applied and catchment settlements where there may have been indiscriminate waste disposals (Suhendan et al., 2010). 

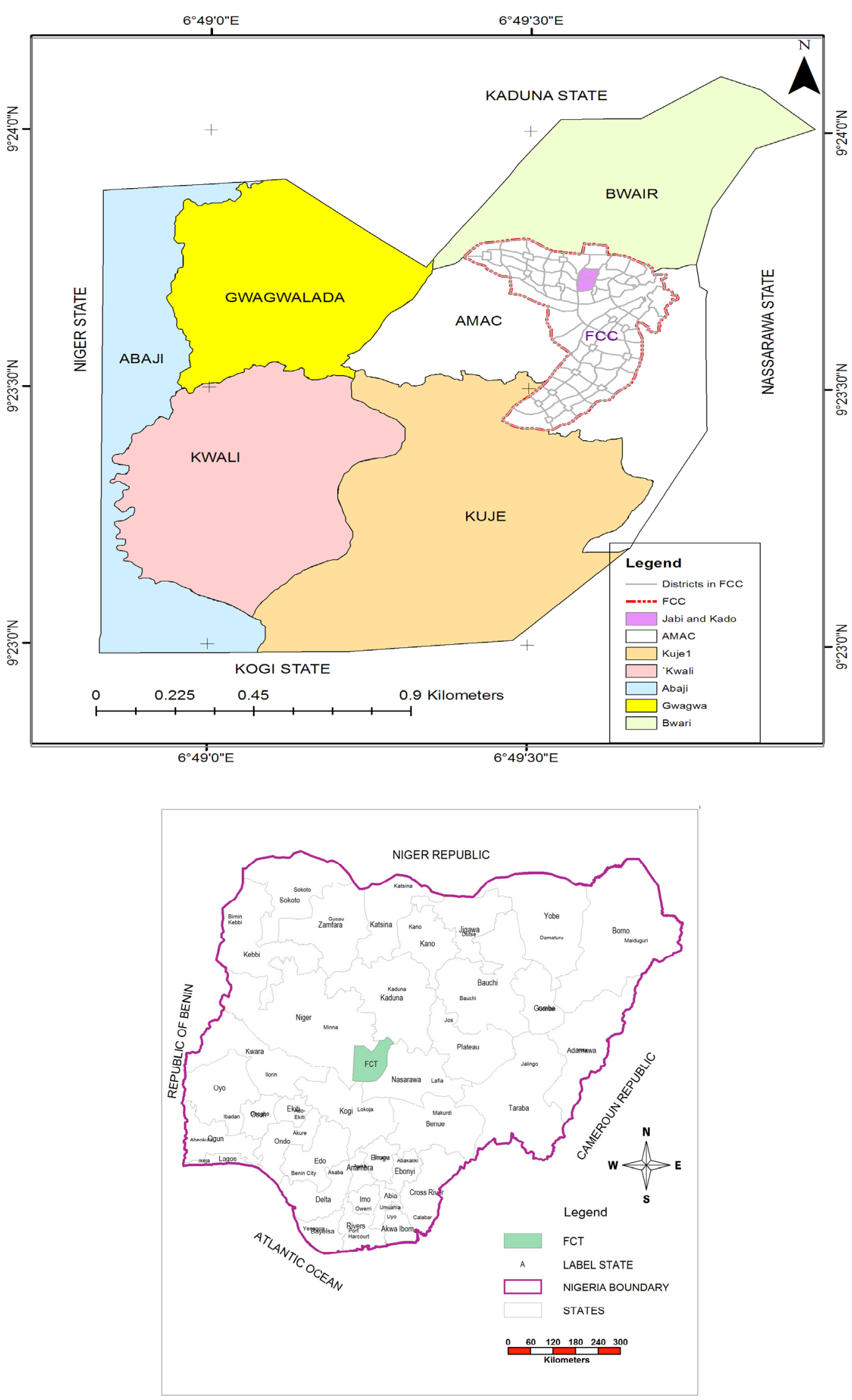

Figure 1. Federal Capital City (FCC) in FCT, Abuja and Nigeria Showing Abuja

Source: Abuja Geographic Information Systems (2018) 
Aquatic environments that pass through cities are usually prone to overloading with a variety of pollutants either through direct or indirect discharges. This situation may be worsened by the indiscriminate disposal of untreated wastes such as industrial effluents and heavily laden sewage. Sewage polluted water bodies carry microorganisms, some of which are pathogenic to humans and animals (Abubakar, 2015). Jabi Lake, like many water bodies in Nigeria, serves as a center for recreation, fishing, and irrigational purposes and as a sink for disposal of municipal wastes.

Many studies have been carried out in the areas of water quality by various people in different locations. Butu (2011); Olofin (1991); Tiri et al. (2011) argued that it is generally accepted the concept that water resources should be developed on the multipurpose basis but rarely has was quality been considered in the planning schemes in developing countries. The major water uses for which large schemes have been designed are power, flood control, and irrigation. It appears, however, that in most developing countries, although water pollution control is very important, it has never been seriously considered in most project designs. There are a few studies on the pollution of Jabi Lake. Umar and Abdullahi (2010) observed high concentration levels of $\mathrm{Ni}, \mathrm{Pb}, \mathrm{Zn}, \mathrm{Cd}$, and $\mathrm{Cu}$ in Jabi Dam sediments using chemical fractionating methods. Umar and Ebong (2013), using water, fish, and sediment samples noted high values of $\mathrm{Zn}$ and $\mathrm{Cd}$ I the water samples from the Lake. Fish samples were also contaminated with $\mathrm{Cu}$. Solomon and Babatunde (2017) stated that Clarias gariepinus from the Lake is subjected to the pollution of its habitat.

The residents of Jabi District and, indeed, the FCT are questioning the current pollution status of the Jabi Lake? A paucity of information exists on the extent of pollution of the Lake. Providing the answers to these questions is the problem of the paper. Since the Lake is used for beneficial purposes, it becomes necessary to assess the pollution of the Lake using some physicochemical parameters and the potential risks to residents and tourists. Therefore, the paper is an attempt to provide an answer to these questions.

Abuja, the Federal Capital Territory (FCT) was created by law in 1976 and intended to build a better capital city than Lagos (Federal Capital Development Authority, 1978, 1979). This study will be carried out in Jabi Lake, which is a natural water body in the Jabi district of Abuja. Jabi Lake, which is a human-made reservoir of water from the foot of Katampe rocks, is located within Kado and Jabi Districts of the Federal Capital Territory (FCT), as shown in Figure 1 (Umar and Ebong, 2013). Its located between Latitudes $9^{\circ} 23^{\prime} 34.30^{\prime \prime} \mathrm{E}$ and $9^{\circ} 23^{\prime} 33.45^{\prime \prime} \mathrm{E}$ North of the Equator and Longitudes 6 $49^{\prime} 34.30^{\prime \prime}$ and $6^{\circ} 49^{\prime} 33.45^{\prime \prime}$ East. The temperature of the area ranging between $30^{\circ} \mathrm{C}$ to $35^{\circ} \mathrm{C}$ annually. Jabi district has an estimated population of 39,876 people (Solomon and Babatunde, 2017;
Ezeamaka, 2015). The temperature in the raining season is between $23^{\circ} \mathrm{C}-30^{\circ} \mathrm{C}$ and $12^{\circ} \mathrm{C}-40^{\circ} \mathrm{C}$ in the dry season (Murray, 2007). Environmental activities around the lake are a mall, a park that serves as a rec reational benefit to occupants of the district. Due to increases in urbanization around the lake area, the initial intention of meeting the water need of FCT residence for which the lake was created was dropped as the lower Usman Dam was constructed in Bwari for servicing the water needs of the Federal Capital Territory (FCT Water Board, 2005). The land-use of the Jabi area is mostly residential and commercial.

An increase in urbanization and socio-economic activities within and around Jabi Lake poses a threat to its pollution with chemicals such as heavy metals. The Lake may have experienced several episodes of heavy metal pollution emanating from flower farming and block molding industries around the lake, as well as the discharge of erosion run-offs into the lake, which may undoubtedly carry municipal wastes. The presence of heavy metals in the lake would lead to bioaccumulation in aquatic life.

This bioaccumulation may have a profound effect on the residents that rely on these aquatic lives, such as fishes and Cray-fish. Consequently, the potential long term impact on public health and ecosystem cannot be ignored.

\section{The Methods}

\section{Types and Sources of Data}

Primary and secondary data were used for this study. The primary data were raw water samples from Jabi Lake. The secondary sources of data used were the Nigerian Industrial Standard (NIS) (2007) and WHO (2010) guidelines for domestic water. Other materials were from other relevant literature and the internet. Maps were obtained from Abuja Geographic Information Systems (AGIS).

\section{Sampling Collection}

To find suitable sites along the Jabi Lake where the research could be executed, certain factors were taken into consideration concerning the potential sites that were investigated. The criteria used include the types and pathways of contamination and anthropogenic activities. The study used a purposive sampling method to select four points. After all the potential sites were visited, the four most suitable selected/designated were marked as the point I to IV were chosen and sampled on a monthly basis from June 2018 to August 2018 from four (4) different points in the lake. This covered only the raining season because of heavy surface flow from the catchment area. The point I - the discharge point of municipal waste. Point II - located at the Jabi Park. Point III - Under the Jabi Bridge. Point IV - the location Near Water Board as shown in Figure 2. A total of 12 samples were collected from the sampling points. 


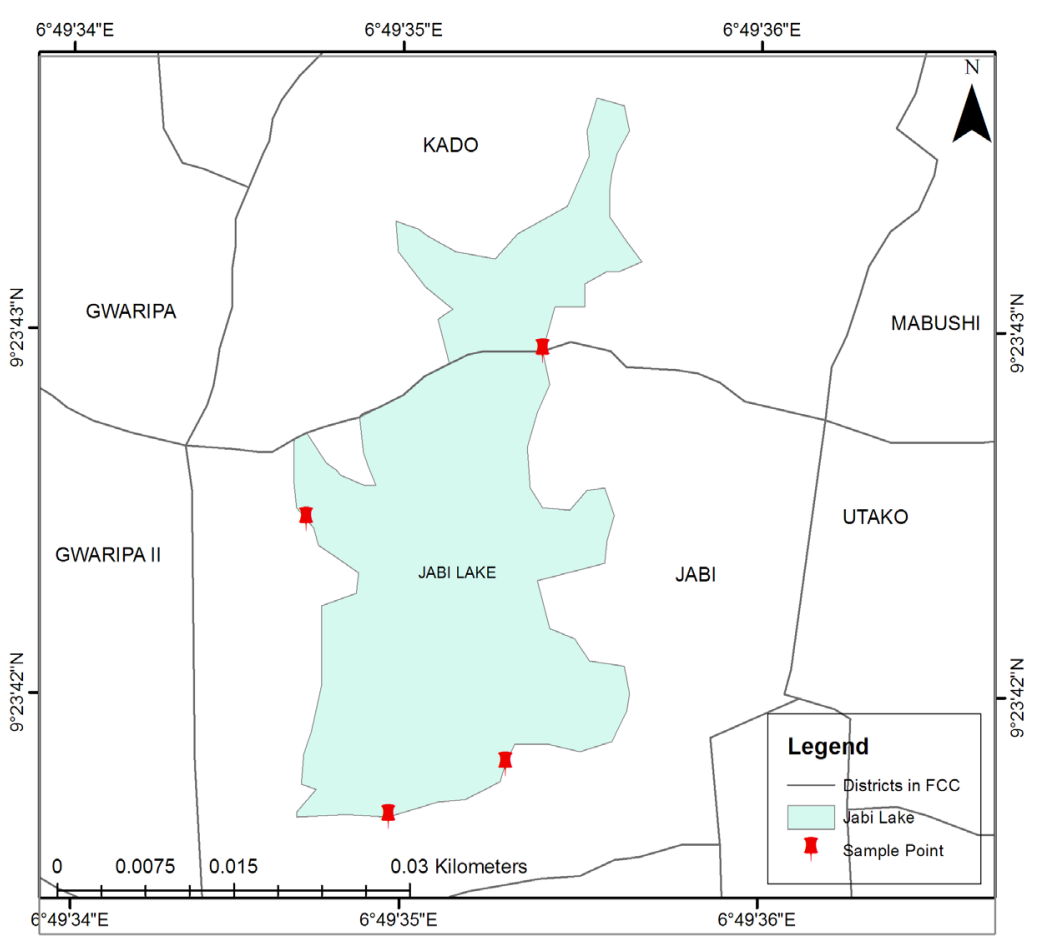

Figure 2. Sampling Points

Source: Fieldwork (2018)

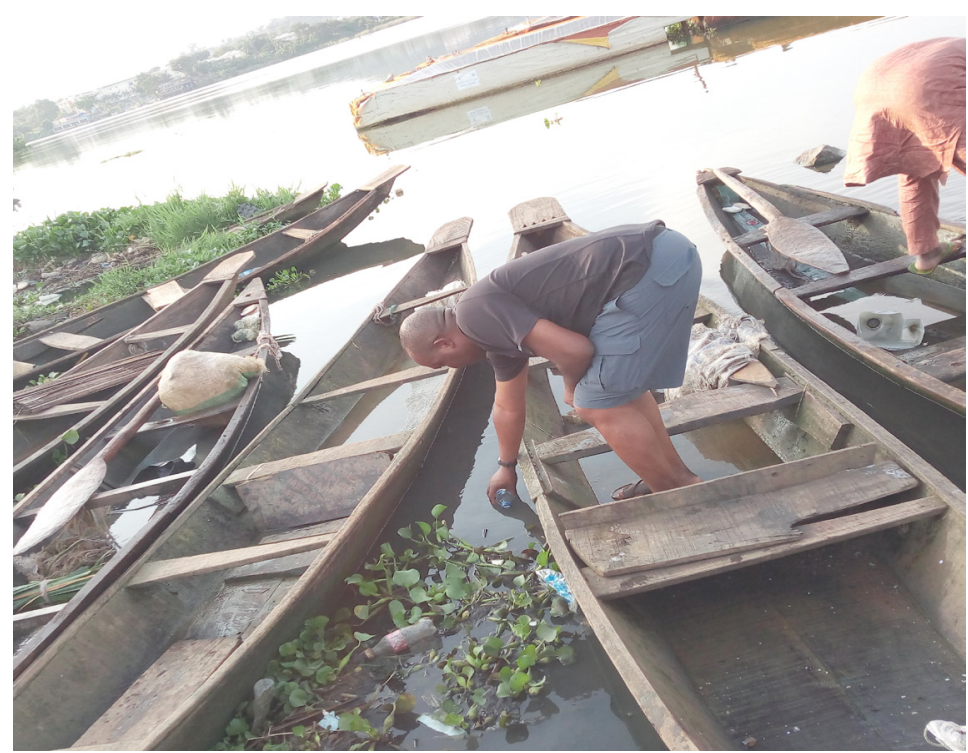

Figure 3. Water Sample Collection

Source: Fieldwork (2018)

The samples were collected from different four points because of the possible mixing of these pollutants in the River. The water samples were collected in clean plastic bottles and kept in the refrigerator before taken to the laboratory within 24 hours. This was done to ensure that the chemicals contained in the samples do not undergo a chemical reaction to form new compounds. To ensure that no foreign substance was introduced into the sample, the plastic bottles were washed with water from the Lake before collection. The uncapped bottle was submerged to a depth of about $10 \mathrm{~cm}$ under the water surface pointing towards the direction of flow until the bottle was completely filled to the brim, and the cap replaced before it was taken out of the water as shown in Figure 3. 


\section{Sample Preparation and AAS Analysis}

Fifty millimeters $(\mathrm{ml})$ of water was measured into a $250 \mathrm{ml}$ beaker, and $15 \mathrm{ml}$ hydrogen chloride $(\mathrm{HCl})$ and nitric acid (HNO3) were added. The beaker and the content were placed on a hot plate, heated at $100 \nabla_{c}$ to dry and digest until brown fumes of $\mathrm{HNO} 3$ escaped. The heating continued until the content was reduced to $10 \mathrm{ml}$. The content was then washed into a $50 \mathrm{ml}$ volumetric flask, and the digest obtained was preserved in a refrigerator until analysis. The flame atomic absorption spectrometer (AAS-buck scientific VGP 210 model) was used in the analysis. The concentrations of the metals were determined in triplicates. The accuracy and precision of the analytical procedure were determined. A series of standards were prepared for instrumental calibration by serial dilution of working solutions (100ppm) prepared from analytical grade stock solutions (1000ppm) from BDH Poole, USA. A standard and blank sample were run after every sample to check for instrumental drift.

\section{Determination of Physicochemical Parameters}

The field meter was checked and calibrated according to the manufacturer's specifications. The variables analyzed were $\mathrm{pH}$, temperature, Electrical Conductivity, total dissolved solids, and turbidity. Standard methods were followed in determining the variables (APHA, 2005). In situ measurement of some of the physicochemical parameters, $\mathrm{pH}$, temperature, total dissolved solids, electrical conductivity, and transparency were measured using Hanna multiparametric meter (model 191300), transparency was measured using Secchi disc (diameter 20.2). Dissolved oxygen, Biological Oxygen Demand, and Chemical oxygen demand of the water sample in $\mathrm{mg} / \mathrm{l}$ were measured titrimetrically using the standard method, as detail in (Aneja, 2005).

\section{Statistical Analysis}

Descriptive statistics (mean, standard deviation) and standard error of the mean were calculated for each water parameter determined for each of the four sampling points. This is to enable us to offer a good descriptive account of the special variation in the water quality of the lake. Analysis of variance was subsequently used to assess further the significance of variation in the quality parameters determined between pairs of sampling stations. This is to enable us to identify the main spatial location that varies significantly amongst the four sampling stations. All of these were calculated using SPSS (version 16.0) statistical package because of its availability and reliability.

\section{Results and Discussions}

The observed values for the 13 parameters tested in the water quality carried out for each of the four sampling points, as shown in Table 1 . The clarity of the natural body of water is an important determinant of its condition and productivity.

The turbidity in water is caused by suspended and colloidal matter such as clay, silts, finely divided organic and inorganic matter, plankton, and another microscopic organism. The mean turbidity ranged between 21.6 - 24.2NTU. Most of the squatter settlers along the course of Jabi Lake might inadvertently discard refuse along the drain that discharges particle into the Lake. The turbidity level of the Lake is above the recommended limits of both WHO and NIS. The range of $\mathrm{pH}$ was between 6.3 and 8.8. $\mathrm{pH}$ was found the same in all the sampling points throughout the study. The range recorded indicates that the water is within neutral range, suggesting a low buffering capacity for the river, and it is within the range for inland waters (6.5-8.5), as reported by Aneja (2005). Abubakar (2015) also reports this range is ideal for aquatic life. The mean value of $\mathrm{pH}$ is within the recommended limits of both WHO and NIS guidelines.

Table 1. Mean Values of Tested Parameters

\begin{tabular}{|c|c|c|c|c|c|c|}
\hline Parameters & Point I & Point II & Point III & Point IV & WHO & NIS \\
\hline Turbidity (NTU) & 23.7 & 24.2 & 21.6 & 23.7 & 5 & 5 \\
\hline Dissolved Oxygen & 8.18 & 6.92 & 4.86 & 4.83 & $8-10$ & $8-10$ \\
\hline Biological Oxygen Demand & 1.96 & 2.24 & 2.09 & 1.59 & NA & NA \\
\hline Chemical Oxygen Demand & 35 & 47.88 & 58.17 & 33.79 & NA & NA \\
\hline Electrical Conductivity ( $\mu \mathrm{s} / \mathrm{cm})$ & 120 & 580 & 611 & 114 & 1000 & 1000 \\
\hline Total Dissolved Solids & 76 & 80 & 75 & 82 & 500 & 500 \\
\hline $\mathrm{pH}$ & 7.3 & 8.8 & 6.3 & 6.8 & $6.5-8.5$ & $6.5-8.5$ \\
\hline Manganese (Mn) mg/l & 0.167 & 0.14 & 0.11 & 0.16 & 0.4 & 0.2 \\
\hline Zinc $(\mathrm{Zn}) \mathrm{mg} / \mathrm{l}$ & 5.51 & 3.64 & - & 5 & 3 & 3 \\
\hline Cadmium (Cd) mg/l & 2.08 & 0.37 & 0.02 & 0.01 & 0.003 & 0.003 \\
\hline Copper $(\mathrm{Cu}) \mathrm{mg} / \mathrm{l}$ & 0.73 & 0.37 & 0.23 & 0.26 & 2 & 1 \\
\hline Nickel (Ni) mg/l & 0.05 & 0.05 & 0.02 & 0.02 & 0.07 & 0.02 \\
\hline $\operatorname{Iron}(\mathrm{Fe}) \mathrm{mg} / \mathrm{l}$ & 0.34 & 0.34 & 0.3 & 0.28 & 0.3 & 0.3 \\
\hline
\end{tabular}

Source: Fieldwork (2018) 
Total dissolved solids (TDS), in a broad sense, reflect the pollutant burden on the aquatic system (Adebayo, 2014). The value of TDS was highest at point IV, which may be attributed to municipal discharge from residents into the lake. Increased TDS, in turn, raises turbidity, thus reducing the transparency of the water (Vivien, Adamu, \& Ayuba, 2012). The study reveals that the mean value of TDS is below the maximum limits of both WHO and NIS guidelines. The value of electrical conductivity (EC) varies substantially among the 4 locations. The mean value of EC is below the recommended limit of both WHO and NIS guidelines.

Dissolved oxygen (DO) is one of the most important factors in stream health. Its deficiency directly affects the ecosystem of a river or lake (AlAmin, 2013). The dissolved oxygen in water depends on several physical, chemical, and microbiological processes. Oxygen is the single most important gas for the most aquatic organism; free oxygen is needed for respiration (Akinyemi and Souley, 2014). The ranging value of DO is from $4.86-8.18$. Heavy rainfall that washes a large quantity of organic matter leads to an increase in turbidity and water depth, thus contributing to the depletion of dissolved oxygen during the wet season. Kemderim (2005), made a similar observation in Kangimi Reservoir, Kaduna. The mean value of DO is below the recommended limits for WHO and NIS guidelines.

The study reveals that the pattern of chemical dissolved oxygen (COD) and biological dissolved oxygen (BOD) are the same as that of EC, with the areas associated with human activities contributing comparatively higher levels into the river than the other area. The similarity in pattern between EC, BOD, and COD, as observed here, is expected since EC is known to greatly influence the levels of chemical oxygen that is demanded by aquatic lives. No available guidelines for COD and BOD.

The mean values of $\mathrm{Mn}$ and $\mathrm{Cu}$ at each sample point are below the permitted limits of the WHO and NIS guidelines; thus, the water of Jabi Lake is not contaminated with these heavy metals. However, $\mathrm{Zn}, \mathrm{Cd}, \mathrm{Ni}$, and $\mathrm{Fe}$ exceed the WHO and NIS recommended limits at each sample point, as shown in Table 1. The mean value of $\mathrm{Cd}$ is above the NIS, and WHO recommended limits for drinking water quality; this means the lake is getting contaminated by $\mathrm{Cd}$. Cadmium has no biological functions to humans, and it has been linked to some health problems, including renal tubular dysfunction, pulmonary emphysema, bone fracture, and reproductive failure in both humans and aquatic lives (Jarup, 2003; Sadiq, 2015).

The mean value of $\mathrm{Ni}$ is above the NIS guidelines indicating that the lake is getting polluted with nickel. Nickel occurs in soils, water, and air. Nickel can exist in compounds of other elements. Industrial and municipal wastes are also sources of nickel (Narayana, 2007). In small quantities, nickel is essential, but in high quantity above the permissible limit, it can be dangerous to human health. It can cause dizziness, congenital disabilities, heart disorders, lung embolism, and cancer (Galadima et al., 2011; Sadiq, 2015). This, therefore, means that the lake water is getting unsafe for fishing and irrigation. The mean value of $\mathrm{Zn}$ is slightly above the WHO and NIS recommended limits; thus, the lake is getting polluted with zinc. Zinc is a trace element that is essential for human health, however, too much zinc can cause eminent health problems such as stomach cramps, skin irritations, vomiting, loss of appetite and anemia (Ali et al., 2005). Umar and Abdullahi (2010) also recorded a high value of $\mathrm{Zn}$ in their study. The pollution of the Lake by Zinc may be attributed to pollutant residual of the boating activities within the lake. The mean value of Fe is also slightly above the recommended limits of WHO and NIS guidelines, indicating that the lake is getting polluted with iron. Rock weathering may be the possible source of iron in the lake.

From the previous discussion, it can be deduced that some of the heavy metal contaminants in the area might have been emanated from sewage input, and domestic discharge. Cadmium is present as an impurity in several products such as phosphate fertilizers, detergents, and refined petroleum products. Metals like iron and zinc are embedded in geological formations, and when these rocks undergo chemical weathering, they are released into the environment where they can be washed into the River (Butu, 2013). Copper is released into the environment from copper products such as wires, pipes, and fossil fuel combustion, which can be drained into the lake. Some of these heavy metals can also enter the river via atmospheric deposition of dust fallout; however, this is an extremely rare source (Sadiq, 2015).

\section{Conclusion}

The study shows that there is a high concentration of some heavy metals ( $\mathrm{Cd}, \mathrm{Cu}, \mathrm{Ni}, \mathrm{Mn}, \mathrm{Zn}$, and $\mathrm{Fe}$ ) in Jabi Lake. $\mathrm{Cd}, \mathrm{Zn}, \mathrm{Fe}$, and $\mathrm{Ni}$ are above the permissible limits of the NIS and WHO guidelines, which is an indication of pollution. The presence of these contaminants in the Lake is caused by anthropogenic activities such as the use of chemicals such as fertilizers and herbicides by farmers, dumping of sewage discharge by the housing estates, dumping of solid wastes by residents and also weathering activities of the soil. Heavy metals are known to be carcinogenic to humans because they bioaccumulate from the intake over the life span; they also affect the growth rate in children and sometimes lead to death. To overcome this problem, the contaminants have to be controlled at the source. Heavy metal pollution is not new, patients suffering from heavy metal poisoning are rarely diagnosed and are usually treated for other diseases. 
In conclusion, the results of this study reveal that Jabi Lake is contaminated with $\mathrm{Zn}$. The study, also reveals an increase in $\mathrm{Cd}, \mathrm{Ni}$ contamination in the lake water. Jabi Lake is not heavily burdened with Mn and $\mathrm{Cu}$, but it should be controlled to avoid excessive concentrations.

The study, therefore, recommends that the appropriate authorities should take proactive measures to stop the discharge of pollutants into the Lake. This could cause very serious deleterious consequences on domestic water supply or increase the cost of treatment at the water and finally destroying the potential for the aquatic organism in the system. The study recommends further studies on the sources and causes of pollutants into Jabi Lake.

\section{References}

Abubakar, H. (2015). Assessment of Physicochemical Parameters along Selected Locations of River Kaduna, Kaduna State, Nigeria, ARC Journal of Academic Research, 1(1): 11-16

Adebayo, O. O. (2014). Evaluation of Spatio-Temporal Characteristics of River Water Quality in Ogun-Osun River Basin in Nigeria Using Geographical Information System and Multivariate Techniques, A Ph.D. Thesis Submitted to the Post Graduate School of University of Ibadan, Nigeria

Akinyemi, J. O., and Souley, S. O. (2014). Monitoring the Quality of Some Sources of Irrigation Water in Different Parts of Ogun State, Nigeria, Proceedings 9 IERI International Conference on Environment Systems Science and Engineering, Pp. 123-128

Al-Amin, M. A. (2013). Water Quality Study of River Kaduna in Nigeria, International Journal of Advanced Research, 1(17): 467-474

Ali, N., Oniye, S. J., Balarabe, M. L., and Auta, J. (2005). Concentration of $\mathrm{Fe}, \mathrm{Cu}, \mathrm{Cr}, \mathrm{Zn}$, and $\mathrm{Pb}$ in Makera Drain, Kaduna, Nigeria, Chemclass Journal, 2: 69-73

Aneja, K. R. (2005). Experiments in Microbiology, Plant Pathology and Biotechnology, New Age Publisher, New Delhi, Pp. 355-370

APHA (2005). Standard Methods for Examination of Water and Waste Water, American Public Health Association, Washington, DC

Butu, A. W. (2011). Sources and Levels of Metal Contaminants in River Kubanni, Zaria, Nigeria, PhD Thesis, Department of Geography Ahmadu Bello University, Zaria, Nigeria

Butu, A. W. (2013). Concentration of Metal Pollutants in River Kubanni, Zaria, Nigeria, Journal of Natural Sciences Research, 3(2): 814 - 824

Butu, A.W., and Sadiq, O.Q. (2016). Assessment of some Heavy Metal Contaminants in River Romi, Kaduna, Nigeria, Nigerian Journal of Tropical Geography, 7(1)

Fatoki, O. S., Lujiza, N., and Ogunfowokan, A. O. (2002). Trace Metal Pollution in Umtata River, Water SA, 28: 183-190

FCT Water Board (2005). Purpose and Intent of the Lower Usman Dam, FCT Water Board Bulletin, 6: 3

Federal Capital Development Authority (FCDA). (1979). The Master Plan for Abuja The New Federal Capital of Nigeria, FCDA, Abuja
Federal Capital Development Authority (FCDA). (1998). Abuja Handbook, FCDA, Abuja

Galadima, A., Garba, Z. N., Leke, L., Al-Mustapha, M. N., and Adam, I. K. (2011). Domestic Water Pollution among Local Communities in Nigeria: Causes and Consequences, European Journal of Scientific Research, 52(4): 592-603

Garba, Z. N., Hamza, S. A., and Galadima, A. (2010). Arsenic Level Speciation in Fresh Water from Karaye Local Government Area, Kano State, Nigeria, International Journal of Chemistry, 20(20): 113-117

Jarup, L. (2003). Hazards of Heavy Metals Contamination, British Medical Bulletin, 68:167-182

Joshua, N. M., and Nazrul, M. I. (2015). Water Pollution and Its Impact on the Human Health, Journal of Environment and Human, 2:1

Kemdirim, E. C. (2005). Studies on the Hydrochemistry of Kangimi Reservoir, Kaduna State, Journal of Ecology, 43: 7-13

Murray, S. (2007). Life of Poverty in Abuja's Wealth, BBC

Narayana, P. (2007). Environmental Pollution: Principles, Analysis and Control, CBS Publisher and Distributor Nigeria

Nigerian Industrial Standard (NIS) (2007). Nigerian Standard for Drinking Water Quality, NIS 554:20, Pp. 16-17

Obilonu, A. N., Chijioke, C., Igwegbe, W. E., Ibearugbulem,O. I., and Abubakar, Y. F. (2013). Water Quality Challenges and Impacts, International Letters of National Sciences, 4: 44-53

Olofin, E. A. (1991). Surface Water Pollution: A Menace to the Quality of life in Urban Area, Paper Presented at the 34th Annual Conference of the Nigerian Geographical Association (NGA), Owerri

Sadiq, O. Q. (2015). Assessment of Heavy Metal Contaminants in River Romi, Kaduna, Nigeria, Unpublished M.Sc. Dissertation, Department of Geography, Nigerian Defence Academy, Kaduna

Sharma, B. K. (2010). Environmental Chemistry, Geol Publishing House, Meerut.

Solomon, R. J., and Babatunde, A. A. (2017). Kidney Analysis of Clarias Gariepinus in Relation to Weight from Jabi Lake, FCT, Abuja, Nigeria, Journal of Biology and Biotechnology, 3(1): 24 - 32

Suhendan, M., Ozkan, O., and Oymak, S. (2010). Trace Metal Contents in Fish Species from Ataturk Dam Lake (Euphrates, Turkey), Turkish Journal of Fisheries and Aquatic Science, 10: 209 - 213

Tiri, A., Belkhiri, L., Brudoukha, A., and Lahbar, N. (2011). Characterization and Evaluation of the Factors Affecting the Geochemistry of Surface Water of Kondiat Medouar Basin, Algeria, African Journal of Environmental Science and Technology, 5 (5): 355 - 362

Umar, M. A., and Abdullahi, I. (2010). Speciation Studies of $\mathrm{Ni}, \mathrm{Pb}, \mathrm{Zn}, \mathrm{Cd}$ and $\mathrm{Cu}$ in Jabi Dam Sediments using Chemical Fractionating Methods, Katsina Journal of Pure and Applied Science, 2(1\& 2): 117 - 122

Umar, M. A., and Ebong, M. C. (2013). Determination of Heavy Metals in Soil, Water, Sediment, Fish and Cray Fish of Jabi Lake in the Federal Capital Territory, Abuja, Nigeria, International Journal of Research in Pure and Applied Chemistry, 2 (7): 25-31 
Vivian, E. L., Adamu, I. C., and Ayuba, K. N. (2012). Effects of Effluent Discharge of Kaduna Refinery on the Water Quality of River Romi, Journal of Research in Environmental Science and Toxicology, 1(3): 41-46

WHO (2010). Chemicals of Health Significance as Described by World Health Organization Guidelines for DrinkingWater Quality (Fourth Edition), WHO, Washington DC 